DOI: https://dx.doi.org/10.18203/2320-1770.ijrcog20213464

\title{
A retrospective study of efficacy and cost efficiency of medical vs. surgical management of abortions in first trimester
}

\author{
Meetangi Agarwal*, Sailatha Ramanujam, Anuradha C. Ramachandran
}

\author{
Department of Obstetrics and Gynecology, Chettinad Hospital and Research Institute, Kelambakkam, Chennai, \\ Tamil Nadu, India
}

Received: 20 June 2021

Revised: 17 July 2021

Accepted: 19 July 2021

\author{
*Correspondence: \\ Dr. Meetangi Agarwal, \\ E-mail: drmeetangiagarwal@gmail.com
}

Copyright: (c) the author(s), publisher and licensee Medip Academy. This is an open-access article distributed under the terms of the Creative Commons Attribution Non-Commercial License, which permits unrestricted non-commercial use, distribution, and reproduction in any medium, provided the original work is properly cited.

\begin{abstract}
Background: The aim of the study was to assess and comparatively evaluate the efficacy of different methods of first trimester abortions (medical, surgical) in terms of its safety, cost and effectiveness.

Methods: We present a retrospective observational research study done at Chettinad hospital and research institute, Kelambakkam Chennai which included a total of 70 patients of first trimester abortions, in the period from June 2019 to June 2020. 55 patients were offered medical treatment (MTOP) and were followed up with a repeat scan after 2 weeks. In cases of failed medical abortion patient underwent curettage. Though, in some cases after an attempt at medical abortion, if the products didn't expel at all within 48 hours, dilatation and evacuation was offered. Transvaginal ultrasound was performed to confirm the success of the treatment. In 15 cases who presented with incomplete abortion, surgical treatment (STOP) was offered. The outcomes considered were successful complete abortions, failed medical abortions, side effects and complications including blood transfusion.

Results: The baseline characteristics of women were similar in both the groups like mean age, parity, history of previous termination of pregnancy (TOP). The success rate in MTOP was 67.2\% and in STOP 100\%. The amount of bleeding experienced was moderate to heavy in MTOP and minimal to moderate in STOP.37 women who underwent only medical termination who returned for the 2-week follow-up, the rate of complete pregnancy termination was $94 \%$ and for the remaining 2 women surgical intervention was required. In the surgical group, at the 2-week follow up, no woman underwent a repeat vacuum aspiration with an efficacy of $100 \%$. No significant difference was found in the mean total cost for the medical and surgical groups after adding the subsequent costs (including additional manual vacuum evacuation).
\end{abstract}

Conclusions: Medical termination of abortion should be preferred over surgical termination as it is safer, cost effective, with fewer complications and high success rate.

Keywords: Abortion, Misoprostol, Dilatation and curettage

\section{INTRODUCTION}

Abortion is defined as the spontaneous or induced termination of pregnancy before fetal viability. ${ }^{1}$ It is a health issue which is dealt with controversies, conflicts and condemnations. The reason why abortion evokes various strong emotions and reactions in a woman is that it reflects the need of the woman to have control over their own bodies, a human rights principle that contradicts dominant patriarchal attitudes and practices of the society and, in some cases, cultural beliefs. ${ }^{2}$ Every individual has the right to decide freely and responsibly without discrimination, coercion and violence the number, spacing and timing of their children, and to have the information and means to do so, and the right to attain the highest standard of sexual and reproductive health 
(ICPD 1994). In India, abortion is simultaneously a highly prevalent and yet highly stigmatized procedure. There remains widespread misinformation, poor access to services and broad variability in abortion counselling practices. Such studies should be done on large scale reaching the unreached. ${ }^{2}$ Traditionally, the late first trimester miscarriage, is terminated by surgical evacuation of the uterus. Surgical method dates back to the late of the 19th century after the first sharp curettes were described. Although, this procedure was introduced to reduce the risk of infection and hemorrhage, it is reported to be associated with many complications including cervical trauma, perforation of the uterus and endometritis. In addition, uterine synechia, reduced fertility, tubal damage and pelvic pain have been reported as long-termcomplications. ${ }^{3}$

In recent times as a result of positive experiences with prostaglandin analog (most commonly used misoprostol), the medical termination of the first trimester miscarriage is accepted as a safe and effective alternative. ${ }^{4}$ However , this method is not without its inherent complications like the need for emergency surgical evacuation in case of retained products, side effects of drugs like fever, lower abdominal pain, vomiting, prolonged hospital stay until complete evacuation, psychological stress to the female, increase in induction abortion time, and the need for additional drugs like analgesics and antipyretics.

Data are lacking from large randomized controlled trials assessing which management option is best for managing miscarriage with respect to complete emptying of the uterine cavity and subsequent uterine infection. Randomized controlled trials have largely been unsuccessful in recruiting large numbers of women, as recruiting women at such an emotional time is difficult and as many as 8 in 9 women express a definite preference for treatment and decline randomization. ${ }^{10}$

\section{$\operatorname{Aim}$}

Aim of the current study was to assess and comparatively evaluate the efficacy of different methods of abortions (medical, surgical) in terms of its safety, cost and effectiveness.

\section{METHODS}

This study was carried out in Chettinad hospital and research institute, Kelambakkam, Chennai. The study design was a retrospective study and it was approved by the institutional ethics committee. 70 study participants were taken who attended the obstetrics and gynaecology clinic in a period of 1 year from June 2019 to June 2020 and underwent either medical or surgical abortions in first trimester. The diagnosis of the missed miscarriages and gestational age were confirmed by trans-vaginal ultrasonography.
All the patients who were admitted in the labour ward seeking medical termination of pregnancy due to various reasons in first trimester and fulfilling all the prerequisites of the MTP act were included. Patients who presented to us with missed abortions, inevitable abortions and incomplete abortions were all included in the study. They were selected only if they were hemodynamically stable with no known coagulopathy or absolute contraindications for the use of prostaglandins (glaucoma, severe asthma, mitral insufficiency and stenosis, and adrenal insufficiency, among others) and no history of allergy or hypersensitivity to misoprostol. Patients who did not meet the above criteria or were having absolute contraindications for the use of prostaglandins (glaucoma, severe asthma, mitral insufficiency and stenosis, and adrenal insufficiency, among others) were excluded

Patients were given the option of undergoing medical or surgical treatment and risks and complications were explained before obtaining a detailed history regarding the last menstrual period, menstrual cycles, past obstetric history, past history of method of abortion, past medical and surgical history, allergy to drugs and treatment history. General, physical and pelvic examination findings were recorded. Routine investigations for the hemoglobin status, blood grouping and Rh typing, serology, trans-vaginal ultrasonography (TVS) for exact gestational age were searched and recorded. The women were informed about the study retrospectively before obtaining and analyzing their data from MRD. Patient's consent was taken over phone.

Out of total 70 women, 55 women received medical method, 15 women received surgical method and 18 women underwent surgical method after failed medical method to evacuate completely the products of conception. In our study, out of 55 in medical method, 33 women received mifepristone (200 $\mathrm{mg}$ orally) under supervision. After 48 hours of mifepristone, vaginal misoprostol in doses of $800 \mathrm{mcg}, 400 \mathrm{mcg}$ and $400 \mathrm{mcg}$ were kept 6 hours apart, as required. 22 women received only vaginal misoprostol. The side effects like heavy bleeding per vaginum, severe cramping, pyrexia, vomiting, head ache, dizziness, and chills were recorded along with the drugs given. A transvaginal ultrasound examination was done 48 hours later in women who failed completely to respond to mifepristone or misoprostol. Surgical evacuation was done for women with persistent gestational sac or with retained products of conception on ultrasound even after 48 hours of medical treatment and were classified as failed medical abortion $(\mathrm{n}=18)$. Meanwhile, women who expelled products of conception completely were asked to review after 2 weeks and a repeat TVS (check scan) was performed. The women with no retained products of conception on check scan were considered successful $(n=37)$. 
Women who underwent primary manual vacuum aspiration/ check curettage were included in surgical termination of pregnancy group (STOP). Bleeding per vaginum among the two groups of women were noted during the process and were classified into none (0-2 days), minimal (<7 days), moderate (7-14 days) and heavy (>14 days). Check curettage was done under short $\mathrm{GA}$, induction was done with injection glycopyrrolate $(0.2 \mathrm{mg})$, injection midazolam $(1 \mathrm{mg})$, injection fentanyl (100 mcg), and injection propofol (dose depending on weight of the patient) intravenously and maintained with $50 \%$ oxygen and $50 \%$ nitrous oxide along with $1.5 \%$ isoflurane. Postoperatively, patient was monitored in the ICU setting for around 4 hours and watched for side effects like laryngospasm, bleeding, aspiration and was then shifted to general ward. All women were prescribed prophylactic antibiotics to prevent postabortal infection.

\section{RESULTS}

The data of total 70 women was collected in our study who underwent termination of pregnancy in a period of one year, of which 55 women received MTOP and 15 women received STOP. Baseline characteristics (Table 1) were similar in both the groups like mean age, parity, history of previous termination of pregnancy (TOP). The success rate (Table 2) in MTOP was $67.2 \%$ and in STOP $100 \%$. The amount of bleeding experienced (Figure 1) was moderate to heavy in MTOP and minimal to moderate in STOP.

Out of the 37 women who underwent only medical termination who returned for the 2-week follow-up, the rate of complete pregnancy termination was $94 \%$ (35/37). For the remaining 2 women surgical intervention was required. In the surgical group, at the 2 week follow up, no woman was found to require a repeat vacuum aspiration. The efficacy reached 100\% (33/33).

No fatality, infection, any adverse drug reaction or anesthesia side effects occurred for the patients of both medical and surgical group. 23 patients complained of lower abdominal pain after administration of misoprostol tablets per vaginally and was relieved with analgesic drugs. After surgical evacuation, the patients were given antibiotic cover. 17 patients complained of pyrexia post misoprostol administration and were treated by antipyretics. The induction abortion interval for the medical group (MTOP) was 5.5 \pm 1.61 hours (mean \pm S.D) and medical group with additional curettage was 7.2 \pm 1.67 (mean \pm S.D).

\section{Cost analysis}

The total cost of treatment in medical group was approx. Rs.2000/- and surgical group was Rs 4000/-. Out of 55 women who underwent medical abortion, 18 women failed to abort and received surgical intervention. The increased costs of these 18 women included cost of IPD registration, operation cost and anesthesia cost which is approx. Rs. 2200/- and sums up to be Rs. 4200/-. The total cumulative costs for these patients increased significantly as compared to the women who did not require surgical intervention. No women from the surgical group required repeat vacuum aspiration. No significant difference was found in the mean total cost for the medical andsurgical groups after adding the subsequent costs (including additional manual vacuum evacuation).

Table 1: Characteristics of termination of pregnancy.

\begin{tabular}{|c|c|c|c|c|c|}
\hline \multicolumn{4}{|c|}{ Medical abortion (n=37) } & \multicolumn{2}{|c|}{$\begin{array}{l}\text { Failed medical } \\
(n=18)+\text { primary } \\
\text { surgical abortion } \\
(n=15)\end{array}$} \\
\hline \multirow[t]{2}{*}{ Age } & \multirow[t]{2}{*}{ Mean \pm SD } & \multicolumn{2}{|c|}{$27.7 \pm 1.87$} & \multicolumn{2}{|c|}{$27.8 \pm 1.97$} \\
\hline & & & $\%$ & $\mathbf{N}$ & $\%$ \\
\hline \multicolumn{6}{|c|}{ Parity } \\
\hline & Primi & 15 & 40.5 & 11 & 33.3 \\
\hline & Multi & 22 & 59.4 & 22 & 66.6 \\
\hline & Total & 37 & 100 & 33 & 100 \\
\hline \multicolumn{6}{|c|}{ Gestage (days) } \\
\hline & $<49$ & 13 & 25.1 & 12 & 36.3 \\
\hline & $>49$ & 24 & 64.86 & 21 & 63.6 \\
\hline & Total & 37 & 100 & 33 & 100 \\
\hline \multicolumn{6}{|c|}{ PREV TOP } \\
\hline & Yes & 6 & 8.57 & 3 & 4.28 \\
\hline & No & 61 & 87.14 & 61 & 87.14 \\
\hline
\end{tabular}

\section{DISCUSSION}

In our study, the success rate for STOP was $100 \%$ and with MTOP it was $67.2 \%$. This result is consistent with the study done by Akkenapally et al which showed success rate with STOP as $100 \%$ and MTOP as $76.9 \% .^{2}$ In another study done by Say et al in department of reproductive health and research, world health organization, Geneva, Switzerland showed the rate of abortions not completed with the intended method was statistically significant higher in the prostaglandin group (2.7, 95\% CI 1.1 to 6.8 ) compared to surgery and concluded prostaglandins used alone seems to be less effective and more painful compared to surgical firsttrimester abortion. ${ }^{9}$ The amount of bleeding experienced in surgical group was minimal to moderate and moderate to heavy in medical group, similar to the studies done by Xia et al. which showed the duration of bleeding lasting for an average of 12.0 \pm 7.9 days in medical group and $4.2 \pm 2.7$ days in surgical group. Women experienced a larger decrease in hemoglobin levels from baseline to two weeks after medical abortion in comparison to surgical abortion. ${ }^{5}$ In another study done by Davis et al done in department of obstetrics and gynecology, Columbia university college of physicians and surgeons, New York showed mean days of bleeding was higher in the medical (14 days) than MVA (9 days) group, but days of spotting (about 10) was similar in both groups. They concluded bleeding after early medical abortion persists longer than 
after MVA and continues longer than previously appreciated regardless of method. ${ }^{6}$

Table 2: Bleeding as reported after the procedure.

\begin{tabular}{|lllll|}
\hline Parameters & \multicolumn{2}{l}{$\begin{array}{l}\text { MTOP (including failed } \\
\text { medical abortion) }\end{array}$} & \multicolumn{2}{l|}{ STOP } \\
\cline { 2 - 5 } & N & \% & N & \% \\
\hline Bleeding & & & & \\
\hline None & 0 & 0 & 0 & 0 \\
\hline Minimal & 10 & 18.18 & 8 & 53.3 \\
\hline Moderate & 40 & 72.7 & 5 & 33.3 \\
\hline Heavy & 5 & 9.09 & 2 & 13.3 \\
\hline Total & 55 & 100 & 15 & 100 \\
\hline
\end{tabular}

Table 3: Success rate among two methods of abortion.

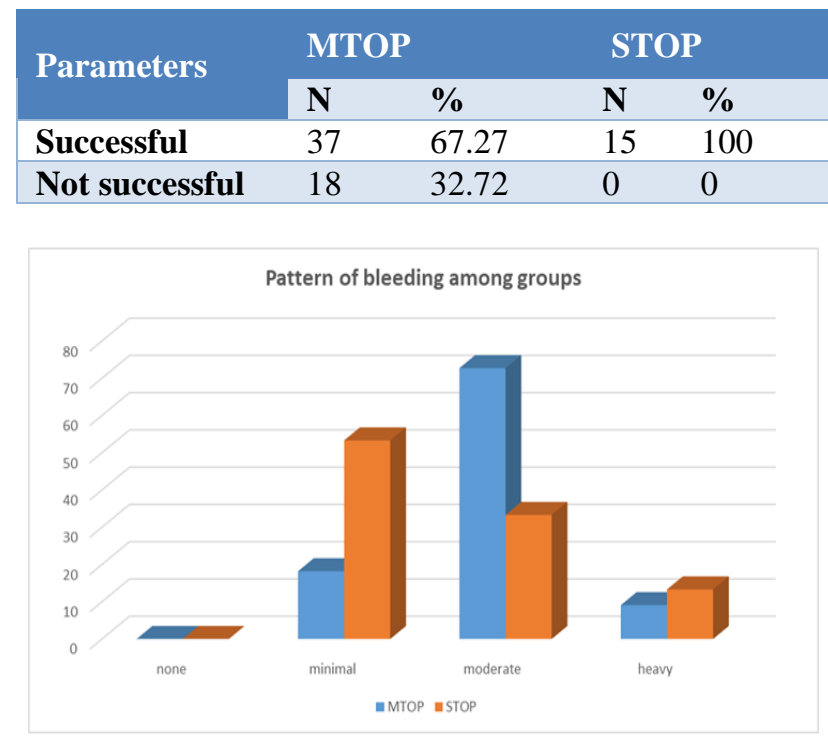

Figure 1: Comparison of bleeding among 2 groups.

It is clear that according to my study the medical treatment for abortion is more cost-effective strategy than the surgical one. This was also concluded in the study done by Nava et al published in PLOS ONE journal in Jan 10, 2019 in Spain. ${ }^{7}$ The estimated overall cost of medical treatment in the present study was Rs. 2000/-, less than that of surgical treatment. However, medical and surgical treatment combined estimated to be around Rs. 4200/- which is similar to that of surgical treatment alone. Another study done by Rausch et al in North shore university hospital, New York demonstrated increased cost of US\$336 for $13 \%$ increased efficacy of surgical management. However, they concluded that surgery is cost effective and more efficacious when performed in an outpatient setting. For incomplete or inevitable abortions medical management is cost effective and more efficacious. $^{8}$

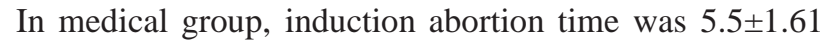
hours, whereas in surgical group, patients were directly taken up for evacuation. These findings are similar to the study done by Shuaib et al published in Alexandria Journal of medicine in 2013 which stated that the disadvantage of medical method is the prolonged induction abortion intervals which indicate an average of two additional days of vaginal bleeding and pain. This also explains increased bleeding and pain in case of medical abortion which is another drawback. ${ }^{3}$ Even though our study had the strength of retrospective study design, nevertheless it was not without limitations. Firstly, patient satisfaction could not be studied as there was no data available regarding the same. Secondly, the long-term problems like uterine synechiae, fertility related problems, etc. in surgical group could not be accessed because of lack of prospective long term follow up.

\section{Table 4: Side effects experienced by women in different groups.}

\begin{tabular}{|llll|} 
& & & $\begin{array}{l}\text { Failed } \\
\text { medical } \\
\text { with }\end{array}$ \\
Parameters & $\begin{array}{l}\text { surgical } \\
(\mathrm{n}=15)\end{array}$ & $\begin{array}{l}\text { Medical } \\
(\mathrm{n}=37)\end{array}$ & $\begin{array}{l}\text { surgical } \\
\text { evacuation } \\
(\mathbf{n}=\mathbf{1 8})\end{array}$ \\
\hline $\begin{array}{l}\text { Miso doses } \\
(\mathbf{m e a n} \pm \text { SD) }\end{array}$ & - & $2.7 \pm 0.94$ & $2.6 \pm 0.9$ \\
\hline
\end{tabular}

\begin{tabular}{llll}
$\begin{array}{l}\text { Induction- } \\
\begin{array}{l}\text { abortion } \\
\text { time } \\
\text { (mean } \pm \text { SD) }\end{array}\end{array}$ & - & $5.5 \pm 1.61$ & $7.2 \pm 1.67$ \\
\hline $\begin{array}{l}\text { Need for } \\
\text { evacuation }\end{array}$ & - & - & 18 \\
\hline $\begin{array}{l}\text { analgesia } \\
\text { need }\end{array}$ & - & 18 & 18 \\
\hline $\begin{array}{l}\text { Infection } \\
\text { Blood }\end{array}$ & - & - & - \\
\hline $\begin{array}{l}\text { transfusion } \\
\text { Cervical } \\
\text { trauma }\end{array}$ & - & - & - \\
\hline $\begin{array}{l}\text { miso side } \\
\text { effects }\end{array}$ & - & - & - \\
\hline $\begin{array}{l}\text { Anaesthesia } \\
\text { side effects }\end{array}$ & - & 10 & 13 \\
\hline
\end{tabular}

\section{CONCLUSION}

Surgical termination of pregnancy may appear more efficient with better patient acceptability as there is no induction abortion interval, decreased bleeding and pain. It has lower rate of drug side effects such as pyrexia, shivering, abdominal pain with shorter length of hospital stay. Patient wouldn't have to go through labour like discomfort. Medical termination of pregnancy on the other hand is safe, cost effective method and chances of PID, secondary infertility, cervical incompetence, anaesthesia related complications etc. can be avoided. Of course, medical termination has its own drawbacks like induction abortion interval is increased, more anxiety, chances of failure which would necessitate subsequent 
surgical evacuation and increased bleeding. But we would still recommend medical termination as the success rate in our study is $67 \%$ and is definitely safer. Hence patient should be counselled to opt for medical over surgical method for abortion after providing them the complete perspective of both the techniques.

Funding: No funding sources Conflict of interest: None declared

Ethical approval: The study was approved by the Institutional Ethics Committee

\section{REFERENCES}

1. Leveno KJW. Obstetrics. 25th ed. USA: Saunders: 2005.

2. Akkenapally P, Kamineni, V. Medical versus surgical termination of early pregnancy: satisfaction with care, emotional impact and acceptability of the procedure. Int J Reprod Contracept Obstet Gynecol. 2016;45:3158-66.

3. Shuaib A, Alharazi A. Medical versus surgical termination of the first trimester missed miscarriage. Alexandria J Med. 2013;49(1):13-6.

4. Chia K, Ogbo V. Medical termination of missed abortion. J Obstet Gynaecol. 2002;22(2):184-6.

5. Xia W, She S, Lam T. Medical versus surgical abortion methods for pregnancy in China: a costminimization analysis. Gynecol Obstet Invest. 2011; 72(4):257-63.
6. Davis A, Westhoff C, De Nonno L. Bleeding patterns after early abortion with mifepristone and misoprostol or manual vacuum aspiration. J Am Med Womens Assoc. 2000;55(3):141-4.

7. Cubo NA, Soto PZ, Haro PA, Hernández HM, Doyague SM, Sayagués MJ. Medical versus surgical treatment of first trimester spontaneous abortion: A cost-minimization analysis. PLOS ONE. 2019;14(1):e0210449.

8. Rausch M, Lorch S, Chung K, Frederick M, Zhang J, Barnhart K. A cost-effectiveness analysis of surgical versus medical management of early pregnancy loss. Fertil Steril. 2012;97(2):355-60.

9. Say L, Kulier R, Gülmezoglu M, Campana A. Medical versus surgical methods for first trimester termination of pregnancy. Cochrane Database Syst Rev. 2005;1:CD003037.

10. Trinder J, Brocklehurst P, Porter R, Read M, Vyas S, Smith L. Management of miscarriage: expectant, medical, or surgical? Results of randomised controlled trial (miscarriage treatment (MIST) trial). BMJ. 2006;332(7552):1235-40.

Cite this article as: Agarwal M, Ramanujam S, Ramachandran AC. A retrospective study of efficacy and cost efficiency of medical vs. surgical management of abortions in first trimester. Int $\mathbf{J}$ Reprod Contracept Obstet Gynecol 2021;10:3429-33. 